\title{
Association of p21 SNPs and risk of cervical cancer among Chinese women
}

\author{
Ning Wang, Shizhuo Wang, Qiao Zhang, Yanming Lu, Heng Wei, Wei Li, Shulan Zhang ${ }^{*}$, Duo Yin and Yangling Ou
}

\begin{abstract}
Background: The p21 codon 31 single nucleotide polymorphism (SNP), rs1801270, has been linked to cervical cancer but with controversial results. The aims of this study were to investigate the role of p21 SNP-rs1801270 and other untested p21 SNPs in the risk of cervical cancer in a Chinese population.

Methods: We genotyped five p21 SNPs (rs762623, rs2395655, rs1801270, rs3176352, and rs1059234) using peripheral blood DNA from 393 cervical cancer patients and 434 controls.

Results: The frequency of the rs1801270 A allele in patients (0.421) was significantly lower than that in controls $(0.494, p=0.003)$. The frequency of the rs3176352 C allele in cases (0.319) was significantly lower than that in controls $(0.417, p<0.001)$.The allele frequency of other three p21 SNPs showed not statistically significantly different between patients and controls. The rs1801270 AA genotype was associated with a decreased risk for the development of cervical cancer $(\mathrm{OR}=0.583,95 \% \mathrm{Cl}: 0.399-0.853, \mathrm{P}=0.005)$. We observed that the three p21 SNPS (rs1801270, rs3176352, and rs1059234) was in linkage disequilibrium (LD) and thus haplotype analysis was performed. The AGT haplotype (which includes the rs1801270A allele) was the most frequent haplotype among all subjects, and both homozygosity and heterozygosity for the AGT haplotype provided a protective effect from development of cervical cancer.

Conclusions: We show an association between the p21 SNP rs1801270A allele and a decreased risk for cervical cancer in a population of Chinese women. The AGT haplotype formed by three p21 SNPs in LD (rs1801270, rs3176352 and rs1059234) also provided a protective effect in development of cervical cancer in this population.
\end{abstract}

Keywords: P21, Single nucleotide polymorphism, Cervical cancer, Haplotype

\section{Background}

Cervical cancer is the second most common cancer in women worldwide [1,2]. The human papilloma virus (HPV) appears to be a necessary factor in the development of almost all cases (>90\%) of cervical cancer [3]. The HPV E6 and E7 proteins are viral genes expressed in virtually all HPV-positive cervical carcinomas, and many experiments have shown that these are cooperative viral oncoproteins [4] that inactivate p53 and retinoblastoma $(\mathrm{pRb})$ tumor suppressors, promoting carcinogenesis $[4,5]$.

HPV infection is relatively common while only a small fraction of those infected develop cancer, suggesting that additional environmental, genetic, or immunological

\footnotetext{
*Correspondence: zsl0909@sina.com

Department of Obstetrics and Gynecology, Shengjing Hospital of China Medical University, Shenyang, China
}

\section{Biomed Central}

factors contribute to the progression to cervical cancer [6,7]. Cell cycle progression is regulated by cyclindependent kinases, crucial for normal growth and differentiation. Disruption of cell cycle control is common in cancer cells and is believed to play an essential role in cancer initiation and development. The cyclindependent kinase inhibitor p21 (also known as WAF1or CIP1) is encoded by the CDKN1A gene located on chromosome $6 \mathrm{p} 21.2[8,9]$. The $\mathrm{p} 21$ protein binds to and inhibits the activity of cyclin-CDK2 or -CDK4 complexes, and disrupts cell cycle progression at G1 phase $[10,11]$. The expression of $\mathrm{p} 21$ is induced by the binding of tumor suppressor protein $\mathrm{p} 53$ to the $\mathrm{p} 21$ promoter [12-14]. The p21 protein can also interact with proliferating cell nuclear antigen (PCNA), a DNA polymerase accessory factor, and plays a regulatory role in $\mathrm{S}$ phase DNA replication and DNA damage repair [15]. 
Therefore, alteration in the p21 functional and/or promoter regions may adversely affect the regulation of cellular proliferation and increase susceptibility to cancer.

Identification of several genetic variants in $\mathrm{p} 21$ have been associated with cervical cancer [16,17]. The p21 single nucleotide polymorphism (SNP) rs1801270C/A, which occurs in codon 31, results in an amino acid substitution of arginine for serine. This polymorphism is located in a highly conserved region of p21 and is expected to affect its molecular function [18]. Prior studies have linked the p21 codon 31 SNP (rs1801270) to cervical cancer, with conflicting results $[19,20]$. In this study, we genotyped five p21 SNPs (rs1801270 at codon 31 , rs762623 and rs2395655 in the promoter region, rs3176352 in an intron, and rs1059234 in the 3' noncoding region) in 393 cervical cancer patients and 434 cancer-free controls to look for any associations between SNP alleles or genotypes and cervical cancer in a Chinese population.

\section{Methods}

Before beginning this study, the study protocol was approved by the Ethics Committee of our hospital (Shengjing Hospital of China Medical University, Shenyang, China).

\section{Subjects}

We ascertained 393 patients with cervical cancer between October, 2008 and September, 2011 at the Shengjing Hospital of China Medical University. Diagnosis of cervical cancer was confirmed by routine histopathological examination. A total of 434 control samples were randomly selected from the physical examination center from the same hospital and during the same period. The selection criteria for the controls included no individual history of cancer, no history of cervical intraepithelial neoplasia, normal cervical cytology and HPV examination, or normal pathological examination of the cervix within the past two years. HPV examination was performed as described previously [21]. At recruitment, written informed consent was obtained from all study subjects.

Age, smoking status, HPV status, and pathological stage of all 393 cervical cancer cases and 434 controls are presented in Table 1. The two groups seemed to be adequately matched in terms of age and smoking. Among the patients, $89.3 \%$ were HPV positive. The patients' disease severity was assessed using the FIGO (1988) cervical cancer staging system (Table 1).

\section{Genotype analysis}

Genomic DNA was isolated from peripheral blood using the Tiangen Blood Genome Kit. Detailed primer and reaction information for the determination of the p21 SNP
Table 1 Demographic and clinical data of the study group

\begin{tabular}{|c|c|c|c|}
\hline & Patients $(n=393)$ & Controls $(n=434)$ & $P^{a}$ \\
\hline & No. (\%) & No. (\%) & \\
\hline \multicolumn{4}{|l|}{$\overline{\text { Age }}$} \\
\hline$\leq 35$ & $82(20.9)$ & $105(24.4)$ & 0.377 \\
\hline $36-50$ & $219(55.7)$ & $241(55.5)$ & \\
\hline$>50$ & $92(23.4)$ & $88(20.3)$ & \\
\hline \multicolumn{4}{|l|}{ Smoking } \\
\hline Never & $371(94.4)$ & $419(96.5)$ & 0.177 \\
\hline Ever & $22(5.6)$ & $15(3.5)$ & \\
\hline \multicolumn{4}{|l|}{ HPV status } \\
\hline $\mathrm{HPV}+$ & $351(89.3)$ & $0(0)$ & \\
\hline HPV- & $42(10.7)$ & $434(100)$ & \\
\hline \multicolumn{4}{|c|}{ Clinical stage ${ }^{b}$} \\
\hline Stage 0 & $213(54.2)$ & & \\
\hline Stage I & $138(35.1)$ & & \\
\hline Stage II & $34(8.7)$ & & \\
\hline Stage III & $7(1.8)$ & & \\
\hline Stage IV & $1(0.3)$ & & \\
\hline
\end{tabular}

genotypes is given in Additional file 1: Table S1. Briefly, genotyping of rs762623 and rs2395655 was determined by DNA sequencing (Additional file 2: Figure S1). Genotyping of rs1801270, rs3176352, and rs1059234 was determined using a PCR-RFLP method. Each PCR reaction consisted of $0.1 \mathrm{mg}$ DNA, $1 \mathrm{U}$ Taq polymerase, 10 $\mathrm{mM}$ Tris- $\mathrm{HCl}$ (pH 8.3), $50 \mathrm{mM} \mathrm{KCl}, 1.0 \mathrm{mM} \mathrm{MgCl} 2,20$ $\mathrm{mM}$ of each dNTP, and $0.2 \mu \mathrm{M}$ of each primer. PCR products were digested with the indicated restriction enzymes and visualized on agarose gels (Additional file 3: Figure S2, Additional file 4: Figure S3, Additional file 5: Figure S4).

\section{Statistical analysis}

Genotype and allele frequencies were used to assess conformity to Hardy-Weinberg equilibrium. Differences in age and smoking status between patients and controls were evaluated using the Chi-square test. The statistical effect of this study was calculated by Gpower 14 software (Faul \& Erdfelder, Bonn, Germany). Post-hoc analysis (affect scale set to 0.2 and $\alpha$ set to 0.05 ) determined the statistical power of this study to be 0.86 . Linkage disequilibrium (LD) between five loci of p21 was estimated by the likelihood-ratio test. A Bayesian statistical method was used to estimate the haplotypes for each subject based on their known genotypes. These analyses were implemented in Haploview software (version 4.2; Massachusetts Institute of Technology, Cambridge, MA). Haplotype construction and haplotype frequency analysis were performed by PHASE (version 2.1) software 
[22]. All other statistical analyses were performed using SPSS 13.0 software (SPSS Inc., Chicago, USA). After Bonferroni correction, differences were deemed significant at $\mathrm{p}<0.01$.

\section{Results}

Association of p21 SNP alleles and genotypes with cervical cancer risk

The frequencies of each allele of the five p21 SNPs (rs1801270, rs762623, rs2395655, rs3176352, and rs1059234) for patients and controls are given in Table 2. After performing Bonferroni correction to eliminate bias of multiple comparison, we found that the frequency of the rs1801270 A allele in cases (0.421) was statistically significantly lower than that found in controls $(0.494 ; \mathrm{p}=$ 0.003). Frequency of the $\mathrm{rs} 3176352 \mathrm{C}$ allele in cases (0.319) was also statistically significantly lower than that in controls $(0.417 ; \mathrm{p}<0.001)$. The frequency of the rs1059234 alleles between cases and controls was close to statistical significance $(\mathrm{p}=0.055)$. The frequencies of the other two polymorphisms were not statistically significant between the two groups (Table 2).

The genotype distributions among both patients and controls (Table 3) were all in accordance with HardyWeinberg equilibrium. We used an unconditional logistic regression model adjusted for age and smoking to find any association between genotypes and the risk of cervical cancer (Table 3). We found that the rs1801270 AA genotype was associated with a decreased risk for

Table 2 Allele frequencies for all five p21 SNPs in cervical cancer patients and controls

\begin{tabular}{|c|c|c|c|c|}
\hline \multirow[b]{3}{*}{ SNP } & Patient alleles & control alleles & \multirow[b]{3}{*}{ OR $(95 \% \mathrm{Cl})$} & \multirow[b]{3}{*}{$\mathrm{P}^{*}$} \\
\hline & $(n=786)$ & $(n=868)$ & & \\
\hline & No. (\%) & No. (\%) & & \\
\hline \multicolumn{5}{|c|}{ rs762623 } \\
\hline A & $151(19.2)$ & $167(19.2)$ & $1.001(0.782-1.281)$ & 0.993 \\
\hline G & $635(80.8)$ & $701(80.8)$ & & \\
\hline \multicolumn{5}{|c|}{ rs2395655 } \\
\hline A & $399(50.8)$ & $406(46.8)$ & $1.139(0.938-1.383)$ & 0.115 \\
\hline G & $387(49.2)$ & $462(53.2)$ & & \\
\hline \multicolumn{5}{|c|}{ rs1801270 } \\
\hline A & $331(42.1)$ & $429(49.4)$ & $0.744(0.613-0.904)$ & 0.003 \\
\hline C & $455(57.8)$ & $439(50.6)$ & & \\
\hline \multicolumn{5}{|c|}{ rs3176352 } \\
\hline C & 251(31.9) & $317(41.7)$ & $0.656(0.533-0.807)$ & 0.000 \\
\hline G & $535(68.1)$ & $551(58.3)$ & & \\
\hline \multicolumn{5}{|c|}{ rs1059234 } \\
\hline C & $422(53.6)$ & $425(48.9)$ & $1.208(0.996-1.466)$ & 0.055 \\
\hline $\mathrm{T}$ & $364(46.3)$ & $443(51.0)$ & & \\
\hline
\end{tabular}

* $\mathrm{P}$ value was adjusted for age and smoking by multiple logistic regressions. After Bonferroni correction, significant $P$ value was $<0.01$.
Table 3 Genotype frequencies for five p21 SNPs in cervical cancer patients and controls

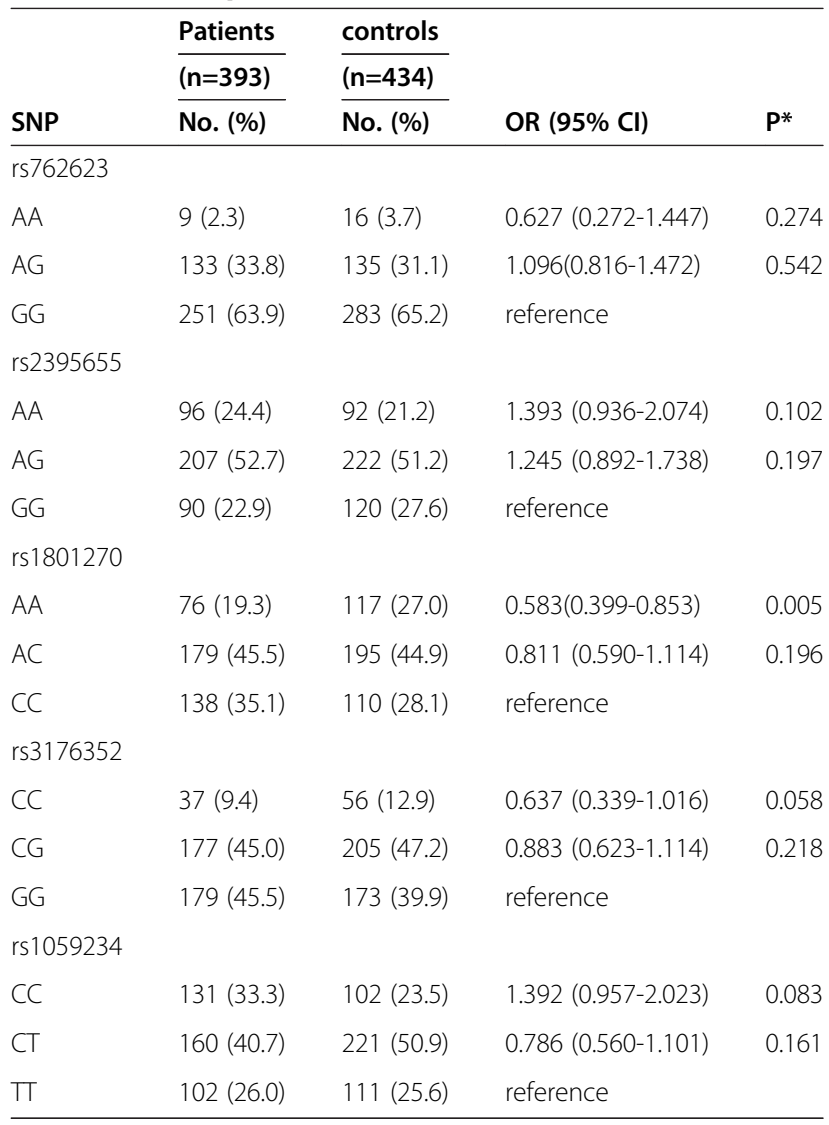

* $\mathrm{P}$ value was adjusted for age and smoking by multiple logistic regressions. After Bonferroni correction, significant $P$ value was $<0.01$.

the development of cervical cancer $(\mathrm{OR}=0.583,95 \% \mathrm{CI}$ : $0.399-0.853, \mathrm{P}=0.005$ ). This observation is consistent with the increased frequency of the rs1801270 A allele among controls. However, we did not observe a similar protective effect of the rs3176352 CC genotype even though the rs3176352 $\mathrm{C}$ allele frequency was lower in controls. No other genotypes of p21 SNPs were found to be associated with the risk of cervical cancer (Table 3).

\section{Haplotype analysis of p21 SNPs}

Linkage disequilibrium (LD) analyses gave D' values and $\mathrm{r}^{2}$ values (Additional file 6: Table S2), which suggested that three of the p21 SNP loci (rs1801270, rs3176352, and rs1059234) were in LD (Figure 1). The most common haplotypes were AGT, CCC, CGC, and CGT, accounting for $94.1 \%$ of the haplotypes observed in all individuals studied (Table 4). The frequency of AGT haplotype in cases $(37.88 \%)$ was slightly lower than that in controls (44.42\%), while the frequency of the CGC and CGT haplotypes were slightly higher in cases $(20.92 \%$ and $7.07 \%$, respectively) than in controls (11.63\% and 3.91\%, respectively; Table 4). 

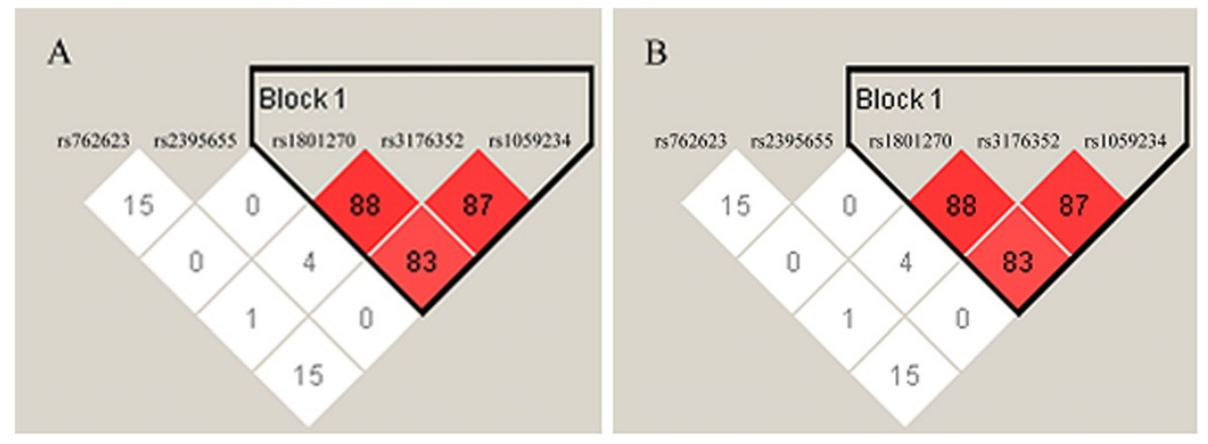

Figure 1 Linkage disequilibrium (LD) plot and block structure of five p21 SNPs in 393 cervical cancer patients (A) and 434 cancer-free controls (B) showing LD of three SNPs. In both groups, the haplotype block is based on confidence intervals D'. Each diamond represents the pairwise magnitude of $L D$, with red indicating strong $L D\left(D^{\prime}>0.8\right)$ and logarithm of odds score $(L O D) \geq 2.0$.

To determine any effect of a particular haplotype on the risk of cervical cancer, we looked at the frequency distribution of the four common p21 haplotypes among cases and controls. To further confirm the association between the p21 haplotype and the risk of cervical cancer, we selected the haplotypes of which the sum frequency in case and control is more than 5\% and analyzed the association between the numbers of variants in each haplotype (ht1-AGT, ht2-CCC, ht3-CGC and ht4-CGT) and the risk of cervical cancer (Table 3). We found that homozygosity or heterozygostiy for the AGT haplotype provides a protective effect (Table 5). The OR value of the homozygous AGT haplotype is 0.643 (95\% CI: $0.434-0.954, \mathrm{P}=0.028$ ), while the OR value of the heterozygous AGT haplotype is 0.636 (95\% CI: $0.467-0.865, \mathrm{P}=0.004)$. Homozygosity of the CGC haplotype significantly increased the risk of cervical cancer $(\mathrm{OR}=3.047$; 95\% CI: 1.788-5.192, $\mathrm{P}=0.000)$, heterozygostiy for the CGC haplotype had no effect on risk of cervical cancer $(\mathrm{P}=0.321)$. Heterozygosity for the CGT haplotype was more common among patients, suggesting an increased risk of cervical cancer among CGT heterozygotes $(\mathrm{OR}=1.846 ; 95 \% \mathrm{CI}: 1.156-2.945, \mathrm{P}=$ 0.010). Homozygosity for the CGT haplotype was not statistically significantly different among groups, possibly because of the small sample size $(\mathrm{P}=0.338)$. The frequency of the CCC haplotype was not statistically

Table 4 Haplotypes of the three p21 SNPs (rs1801270, rs3176352, and rs1059234) in patients and controls

\begin{tabular}{|c|c|c|c|}
\hline \multicolumn{2}{|c|}{ Haplotype } & \multirow{2}{*}{$\frac{\text { Case }(n=393)}{\text { Percentage }(\%)(95 \% \mathrm{Cl})}$} & \multirow{2}{*}{$\begin{array}{l}\text { Control }(n=434) \\
\text { Percentage }(\%)(95 \% \mathrm{Cl}\end{array}$} \\
\hline ht & Haplotype & & \\
\hline 1 & AGT & $37.88(37.68-38.07)$ & $44.42(44.18-44.65)$ \\
\hline 2 & $\mathrm{CCC}$ & $29.30(29.03-29.57)$ & $33.11(32.85-33.36)$ \\
\hline 3 & CGC & $20.92(20.69-21.15)$ & $11.63(11.41-11.86)$ \\
\hline 4 & CGT & $7.07(6.88-7.26)$ & $3.91(3.71-4.11)$ \\
\hline 5 & AGC & $2.20(2.05-2.36)$ & $3.52(3.40-3.63)$ \\
\hline
\end{tabular}

Haplotypes with overall estimated frequency $<3 \%$ are not shown. significantly different among the two groups and was therefore not associated with risk of cervical cancer in this population.

\section{Discussion}

This study looked for an association between five p21 SNPs (rs1801270, rs762623, rs2395655, rs3176352, rs1059234) and the risk of cervical cancer in a Chinese population. Studies have suggested an association between the p21 codon 31 polymorphism (rs1801270) and susceptibility to cancer, but with conflicting results $[17,20,23,24]$. Roh [17], Lee [23] and Jiang [24] found A

Table 5 Haplotypes of the three p21 SNPs in LD (rs1801270, rs3176352, and rs1059234) in patients and controls

\begin{tabular}{|c|c|c|c|c|}
\hline haplotype & $\begin{array}{l}\frac{\text { Patients }}{(n=393)} \\
\text { No. }(\%)\end{array}$ & $\frac{\frac{\text { controls }}{(n=434)}}{\frac{\text { No. }(\%)}{}}$ & OR $(95 \% \mathrm{Cl})$ & $P^{* a}$ \\
\hline \multicolumn{5}{|l|}{ ht1-AGT } \\
\hline ht $1 /$ ht 1 & $67(17.0)$ & $87(20.0)$ & $0.643(0.434-0.954)$ & 0.028 \\
\hline ht1/- & $166(42.2)$ & $215(49.5)$ & $0.636(0.467-0.865)$ & 0.004 \\
\hline $\begin{array}{l}-/- \\
h+2-\text { CCC }\end{array}$ & $160(40.7)$ & $132(30.4)$ & reference & \\
\hline ht2/ht2 & $26(6.6)$ & $41(9.4)$ & $0.628(0.368-1.072)$ & 0.088 \\
\hline ht2/- & $183(46.6)$ & $210(48.4)$ & $0.865(0.650-1.151)$ & 0.321 \\
\hline $\begin{array}{l}-/- \\
h+3-C G C\end{array}$ & $184(46.8)$ & $183(42.2)$ & reference & \\
\hline ht3/ht3 & $51(13.0)$ & $21(4.8)$ & $3.047(1.788-5.192)$ & 0.000 \\
\hline ht3/- & $59(15.0)$ & $56(12.9)$ & $1.322(0.888-1.970)$ & 0.169 \\
\hline $\begin{array}{l}-/- \\
\text { ht4- CGT }\end{array}$ & $283(72.0)$ & $357(82.3)$ & reference & \\
\hline ht4/ht4 & $3(0.8)$ & $1(0.2)$ & $3.054(0.311-29.936)$ & 0.338 \\
\hline ht4/- & $50(12.7)$ & $32(7.4)$ & $1.846(1.156-2.945)$ & 0.010 \\
\hline$-1-$ & $340(86.5)$ & 401 (92.4) & reference & \\
\hline
\end{tabular}


allele seem to be a risk factor of cervical cancer, while Bhattacharya [20] and Tian [25] demonstrated C allele seem to be the risk factor. We found that the rs1801270 AA genotype and A allele occur more frequently in cancer-free controls, and seem to have a significant protective effect in Chinese women. Our results with the rs1801270 SNP are consistant with some previous reports [20,25], but differ from others $[17,19,23,26]$, which found a deleterious effect of the rs1801270 A allele in cervical cancer. This discrepancy could be due to ethnic differences or sample size. Further, large-scale studies will be needed to validate the role of the p21 codon 31 SNP in cervical cancer.

Of the five p21 SNPs studied, three (rs1801270, rs3176352, and rs1059234) were found to be in linkage disequilibrium (LD). Haplotype analysis of these three p21 SNPs showed that haplotype AGT (which includes the rs1801270 A allele) occurs less frequently in cervical cancer patients than in controls. Our results suggest that both homozygosity and heterozygosity of the haplotype AGT may reduce the risk of cervical cancer in Chinese women. However, the heterozygosity of the haplotype CGT increases the risk of cervical cancer. In the current study, we found the association of the other two loci (rs3176352 and rs1059234) and cervical cancer tended to statistical significance. However, the role of the two p21 polymorphisms needs to be studied in a larger cervical cancer patient cohort in the future.

The molecular mechanism underlying the protective effect of the rs1801270 A allele in cervical cancer is unclear. This C/A SNP within the p21 codon 31 results in a substitution of arginine for serine in a conserved region of the protein and may affect the DNA binding affinity and thus physiological function of p21 [27]. The p21 protein plays a role in cell cycle regulation. It binds to cyclin-CDK complexes to arrest cell cycle progression at G1 phase. The transcription of p21 is partially regulated by $\mathrm{p} 53$, which binds to the $\mathrm{p} 21$ promoter and induces expression of $\mathrm{p} 21$. Therefore, functional domains as well as the promoter region of $\mathrm{p} 21$ could be affected by SNPs and lead to altered p21 functionality [26]. The rs2395655 SNP is located in the transcription factor E2F binding region. The rs1059234 SNP occurs in the 3'-non coding region and may affect p21 mRNA stability. Although our results do not find an association between these SNPs and cervical cancer, the molecular mechanism(s) through which p21 SNPs affect risk of cervical cancer is a field that should be pursued further.

Studies of p21 expression in cervical cancer have reported higher levels of expression of p21 in cancer tissue compared to normal tissue [28,29], while others showed there is no association between the expression of p21 and the pathological features of cervical cancer [30]. After infection with HPV, the E6 protein of HPV promotes p53 degradation and thus inhibits p21 expression and function. Loss of $\mathrm{p} 21$ results in decreased ability of the cell to stop cell cycle progression, possibly leading to carcinogenesis. However, the molecular mechanisms that mediate carcinogenesis are very complex, and this is not the only plausible explanation of the relationship between $\mathrm{p} 21, \mathrm{p} 53, \mathrm{HPV}$, and cancer.

\section{Conclusion}

In conclusion, our study showed a significant association between the A allele of the p21 rs1801270 SNP and decreased risk of cervical cancer in a Chinese population. Furthermore, a haplotype containing the rs1801270 A allele was also associated with decreased risk of cervical cancer in this population. The molecular mechanisms underlying this association remain to be determined.

\section{Additional files}

Additional file 1: Table S1. Methods used for p21 SNP genotyping.

Additional file 2: Figure S1. Sample sequence tracing of rs762623 and rs2395655 SNPs showing homozygosity for each allele (top and bottom) or heterozygosity (middle).

Additional file 3: Figure S2. PCR-RFLP analysis of p21 SNP rs1801270A/ C. The $310 \mathrm{bp} \mathrm{PCR} \mathrm{products} \mathrm{were} \mathrm{digested} \mathrm{by} \mathrm{Bgll,} \mathrm{and} \mathrm{presence} \mathrm{of} \mathrm{the}$ $\mathrm{C}$ allele resulted in two bands of sizes 239 and $71 \mathrm{bp}$. Electrophoresis was performed in 3\% agarose gel.

Additional file 4: Figure 3. PCR-RFLP analysis of p21 SNP rs3176352A/ C. The $448 \mathrm{bp}$ PCR products were digested by ApaLI, and presence of the $C$ allele resulted in two bands of sizes 289 and 159 bp. Electrophoresis was performed in $2.5 \%$ agarose gel.

Additional file 5: Figure S4. PCR-RFLP analysis of p21 SNP rs1059234T/ C. The 480 bp PCR products were digested by Pstl, and presence of the C allele resulted in two bands of sizes 291 and 189 bp. Electrophoresis was performed in 2.5\% agarose gel.

Additional file 6: Table S2. Pairwise linkage disequilibrium analysis for all five p21 SNPs for all subjects studied.

\section{Abbreviations}

HPV: Human Papillomavirus; SNP: Single nucleotide polymorphism; HWE: Hardy-Weinberg Equilibrium; MAF: Minor allele frequency; PCRRFLP: Polymerase chain reaction-restriction fragment length polymorphism; LD: Linkage disequilibrium; FIGO: International Federation of Gynecology and Obstetrics.

\section{Competing interests}

The authors declare no conflict of interest.

\section{Authors' contributions}

NW participated in the design of the study and sequencing. SW contributed to PCR-RFLP. QZ carried out sample collection and management. YL participated in statistical analysis. HW carried out DNA extraction. WL participated in sequencing. SZ participated in the design of the study. YD participated in statistical analysis. OY contributed to PCR-RFLP. All authors read and approved the final manuscript.

\section{Acknowledgments}

This study was supported by the National Nature Science Foundation of China (No. 30973191 and 81202047), Science and Technology Program of Liaoning Province (No.2008225004), Peak Medical Construction Special Project of Liaoning Province (No.2010696), Science and Technology Program of Shenyang City (No.F11-262-9-15) and Free Researcher Project of Shengjing Hospital (No.200806). 
Received: 17 March 2012 Accepted: 8 November 2012

Published: 11 December 2012

\section{References}

1. Ferlay J, Shin HR, Bray F, Forman D, Mathers C, Parkin DM: Estimates of worldwide burden of cancer in 2008. GLOBOCAN 2008. Int J Cancer 2010, 127:2893-2917.

2. Jemal A, Bray F, Center MM, Ferlay J, Ward E, Forman D: Global cancer statistics. CA Cancer J Clin 2011, 61:69-90.

3. Walboomers JM, Jacobs MV, Manos MM, Bosch FX, Kumme JA, Shah KV, et al: Human papillomavirus is a necessary cause of invasive cervical cancer worldwide. J Pathol 1999, 189:12-19.

4. Munger $\mathrm{K}$, Baldwin A, Edwards KM, Hayakawa H, Nguyen $\mathrm{CL}$, Owens M, et al: Mechanisms of human papillomavirus-induced oncogenesis. J Virol 2004, 78:11451-11460

5. Beaudenon S, Huibregtse JM: HPV E6, E6AP and cervical cancer. BMC Biochem 2008, 9(1):S4.

6. Magnusson PK, Sparen P, Gyllensten UB: Genetic link to cervical tumours. Nature 1999, 400:29-30.

7. Apple RJ, Erlich HA, Klitz W, Manos MM, Becker TM, Wheeler CM: HLA DR-DQ associations with cervical carcinoma show papillomavirus-type specificity. Nat Genet 1994, 6:157-162.

8. Harper JW, Adami GR, Wei N, Keyomarsi K, Elledge SJ: The p21 Cdk-interacting protein Cip1 is a potent inhibitor of G1 cyclin-dependent kinases. Cell 1993, 75:805-816.

9. El-Deiry WS, Tokino $T$, Velculescu VE, Levy DB, Parsons $R$, Trent JM, et al: WAF1, a potential mediator of p53 tumor suppression. Cell 1993, 75:817-825.

10. Gartel AL, Serfas MS, Tyner AL: p21-negative regulator of the cell cycle. Proc Soc Exp Biol Med 1996, 213:138-149.

11. Harada K, Ogden GR: An overview of the cell cycle arrest protein, p21 (WAF1). Oral Oncol 2000, 36:3-7.

12. Jung YS, Qian $Y$, Chen $X$ : Examination of the expanding pathways for the regulation of p21 expression and activity. Cell Signal 2010, 22:1003-1012.

13. Abbas T, Dutta A: p21 in cancer: intricate networks and multiple activities. Nat Rev Cancer 2009, 9:400-414.

14. Santiago-Raber ML, Lawson BR, Dummer W, Barnhouse M, Koundouris S, Wilson CB, et al: Role of cyclin kinase inhibitor p21 in systemic autoimmunity. J Immunol 2001, 167:4067-4074.

15. Prives C, Gottifredi V: The $\mathrm{p} 21$ and PCNA partnership: a new twist for an old plot. Cell Cycle 2008, 7:3840-3846.

16. Santos AM, Sousa H, Pinto D, Portela C, Pereira D, Catarino R, et al: Linking TP53 codon 72 and P21 nt590 genotypes to the development of cervical and ovarian cancer. Eur J Cancer 2006, 42:958-963.

17. Roh J, Kim M, Kim J, Park N, Song Y, Kang S, et al: Polymorphisms in codon 31 of p21 and cervical cancer susceptibility in Korean women. Cancer Lett 2001, 165:59-62.

18. Chedid M, Michieli P, Lengel C, Huppi K, Givol D: A single nucleotide substitution at codon 31 (Ser/Arg) defines a polymorphism in a highly conserved region of the p53-inducible gene WAF1/CIP1. Oncogene 1994, 9:3021-3024.

19. Harima $Y$, Sawada S, Nagata K, Sougawa M, Ostapenko V, Ohnishi T: Polymorphism of the WAF1 gene is related to susceptibility to cervical cancer in Japanese women. Int J Mol Med 2001, 7:261-264.

20. Bhattacharya P, Sengupta S: Lack of evidence that proline homozygosity at codon 72 of p53 and rare arginine allele at codon 31 of p21, jointly mediate cervical cancer susceptibility among Indian women. Gynecol Oncol 205, 99:176-182

21. Liu X, Zhang S, Ruan Q, Ji Y, Ma L, Zhang Y: Prevalence and type distribution of human papillomavirus in women with cervical lesions in Liaoning Province, China. Int J Gynecol Cancer 2010, 20:147-153.

22. Stephens M, Smith NJ, Donnelly P: A new statistical method for haplotype reconstruction from population data. Am J Hum Genet 2001, 68:978-989.

23. Lee JE, Lee SJ, Namkoong SE, Um SJ, Sull JW, Jee SH, et al: Gene-gene and gene-environmental interactions of p53, p21, and IRF-1 polymorphisms in Korean women with cervix cancer. Int J Gynecol Cancer 2004, 14:118-125.

24. Jiang P, Liu J, Li W, Zeng X, Tang J: Role of p53 and p21 polymorphisms in the risk of cervical cancer among Chinese women. Acta Biochim Biophys Sin (Shanghai) 2010, 42:671-676.
25. Tian Q, Lu W, Chen H, Ye F, Xie X: The nonsynonymous single-nucleotide polymorphisms in codon 31 of p21 gene and the susceptibility to cervical cancer in Chinese women. Int J Gynecol Cancer 2009, 19:1011-1014

26. Roh JW, Kim BK, Lee CH, Kim J, Chung HH, Kim JW, et al: P53 codon 72 and p21 codon 31 polymorphisms and susceptibility to cervical adenocarcinoma in Korean women. Oncol Res 2010, 18:453-459.

27. Facher EA, Becich MJ, Deka A, Law JC: Association between human cancer and two polymorphisms occurring together in the p21Waf1/Cip1 cyclindependent kinase inhibitor gene. Cancer 1997, 79:2424-2429.

28. Werness BA, Wang HQ, Chance J, Goldstein DJ: p53-independent expression of p21waf1/cip1 in preinvasive and invasive squamous neoplasms of the uterine cervix. Mod Pathol 1997, 10:578-584.

29. Milde-Langosch K, Riethdorf S, Kraus-Poppinghaus A, Riethdorf L, Loning T: Expression of cyclin-dependent kinase inhibitors p16MTS1, p21WAF1, and p27KIP1 in HPV-positive and HPV-negative cervical adenocarcinomas. Virchows Arch 2001, 439:55-61.

30. Graflund M, Sorbe B, Karlsson M: Immunohistochemical expression of p53, bcl-2, and p21(WAF1/CIP1) in early cervical carcinoma: correlation with clinical outcome. Int J Gynecol Cancer 2002, 12:290-298.

\section{doi:10.1186/1471-2407-12-589}

Cite this article as: Wang et al:: Association of p21 SNPs and risk of cervical cancer among Chinese women. BMC Cancer 2012 12:589.

\section{Submit your next manuscript to BioMed Central and take full advantage of:}

- Convenient online submission

- Thorough peer review

- No space constraints or color figure charges

- Immediate publication on acceptance

- Inclusion in PubMed, CAS, Scopus and Google Scholar

- Research which is freely available for redistribution
C) BioMed Central 